\title{
The Effect of the Family's Socioeconomic Factors on Nutrition of Elementary School Children
}

\author{
Fereshteh Farzianpour ${ }^{1 *}$, Ali Reihani ${ }^{1}$, Seyyed Mostafa Hosseini' ${ }^{2}$, \\ Halea Saderzadeh Yaganeh ${ }^{3}$, Seyead Shahab Hosseini ${ }^{4}$ \\ ${ }^{1}$ Department of Health Management and Economics, School of Public Health, Tehran University of Medical \\ Sciences, Tehran, Iran \\ ${ }^{2}$ Department of Epidemiology and Statistics, School of Public Health, Tehran University of Medical Sciences, \\ Tehran, Iran \\ ${ }^{3}$ Department of Nutrition, School of Public Health, Tehran University of Medical Sciences, Tehran, Iran \\ ${ }^{4}$ Tehran University, Tehran, Iran \\ Email: farzianp@sina.tums.ac.ir, farzianp2@yahoo.com
}

Received 29 August 2014; revised 18 October 2014; accepted 4 November 2014

Copyright (C) 2014 by authors and Scientific Research Publishing Inc.

This work is licensed under the Creative Commons Attribution International License (CC BY).

http://creativecommons.org/licenses/by/4.0/

(c) (i) Open Access

\section{Abstract}

Introduction: Anthropometric indices are used for assessing the nutrition status of people and societies. The indices determine the growth of the child's nutrition status, his socioeconomic status and his quality of life. This research aims to study the anthropometric indices of elementary school children in the Iranian city of Piranshahr using the Body Mass Index (BMI) and waist circumference in the first six months of 2011. Methods: In this descriptive-analytical cross-sectional study, 1803 students aged between 7 and 11 in Piranshahr were studied. Multi-stage cluster sampling was used. The research setting was an elementary school in Piranshahr. Demographic data were collected through interviews and record in questionnaires. A Secca stadiometer was used to measure the height of each student standing without shoes (accuracy of 0.1 centimeter). The weight was measured using a spring scale with an accuracy of 0.1 kilogram with the least possible clothes on. The weight was divided by the square of height (square meter) to calculate BMI. To determine overweight and obesity, BMI percentiles of Center for Disease Control (CDC) were used. In order to use appropriate tests, the normality and equality of variances were measured by Leven and K-S tests, respectively. Results: The study found that 231 children $(12.8 \%)$ were at risk of overweight and 96 children $(5.3 \%)$ were overweight. Conclusion: There was a meaningful difference between boys and girls in terms of nutrition status of BMI, father's higher education level,

\footnotetext{
"Corresponding author.
}

How to cite this paper: Farzianpour, F., Reihani, A., Hosseini, S.M., Yaganeh, H.S. and Hosseini, S.S. (2014) The Effect of the Family's Socioeconomic Factors on Nutrition of Elementary School Children. Health, 6, 2657-2667. 
shortness, abdominal obesity and family history of obesity, and father's jobs (P < 0.0001).

\title{
Keywords
}

\author{
Anthropometric, Socioeconomic Factors, Nutrition Status, Elementary School Children, \\ Piranshahr, Iran
}

\section{Introduction}

The importance of obesity in childhood and adolescence is not limited to the early physical and mental complications, but also includes the increased risk of obesity in adulthood, increased risk of diseases and mortality and a heavy financial burden on the society [1]. Obesity constitutes the most important nutritional disorder in developed countries and has been on the rise during the last few decades [1] [2]. Previous studies indicate that adulthood obesity is directly associated with obesity during childhood and adolescence [2]. Obese children are 2 - 3 times more likely to turn into obese adults [3]. Obesity in children causes certain complications such as depression, unsociability, low self-esteem, frustration, and obstructive sleep apnea. Obesity increases the risk of cardiovascular diseases, diabetes and hypertension [4]. In developed countries, obesity is most often observed in children with high socioeconomic status [5] [6]. In certain European countries, including Spain, Portugal, England, Greece, France and Sweden, children obesity is reportedly rising [7]. Similarly, the economic development in some Asian countries such as South Korea, Singapore, Thailand, and Indonesia has resulted in an increased rate of childhood obesity [8]-[12]. In the United States, the prevalence of obesity rose from $13.8 \%$ to $16 \%$ in girls and from $14 \%$ to $16.2 \%$ in boys from 1999 to 2004 [4]. In Iran, obesity constitutes a serious health problem in connection with the worldwide obesity pandemic [13].

Many studies have been conducted in Iran to address obesity in children and adolescents, yielding different prevalence rates [14]. The results suggest that obesity is becoming more prevalent [14]. The prevalence of obesity has been reported $1.8 \%$ in 10-year old school girls of Kerman, $4.8 \%$ and $6.5 \%$ in 11 and 14-year old male students of Khoshab, respectively, 2.8\% in male students of Zanjan, and 4.9\% in boy and girl students of Rafsanjan [15]-[17]. International reports yield similar results. A study on school children in Kalambar indicated that about $3.4 \%$ of boys and $3.1 \%$ of girls were obese [18] [19]. A Venezuelan study reported that $4.57 \%$ of school children aged 6 - 12 years suffered from obesity [20]. The problem of overweight and obesity is found in many children in both developed and developing countries. However, many communities report short stature, low weight and excessive thinness as the more common nutritional problems [16]-[21].

Thinness and obesity are multifactorial issues associated with factors such as genetics and behavior [18]-[21]. The behavioral components include physical activity and nutrition, both of which are influenced by social, cultural and environmental factors. The pattern of physical activity in children has shifted due to increasing amount of time spent in watching television or playing video games [19]-[22]. Normal growth provides the most important and easiest way to assess a child's health, and it can be accessed through measurements of height, weight and body mass index (BMI). There is ample evidence suggesting retarded growth and nutritional shortness in school age children are associated with learning, intelligence and educational success of the children [20]-[23]. Inappropriate nutrition and unhealthy dietary habits impact children's physical growth, learning abilities, and behavior [21]-[24]. Malnutrition is an important factor predisposing the child to infections. It must be noted that poor growth is not the only factor affecting the development of intelligence; a child's development depends on many socioeconomic factors, as well. Nutritional status constitutes one of the best indices of health in a society, and its relative measurement (anthropometry) is a cost-effective, reliable method to assess the health of the individual and the society [22]-[25].

Although some studies have been conducted on height and weight of children in Iranian cities of Shiraz, Tehran, Isfahan and Mashhad, it is unfortunate that children's growth monitoring is still performed using American or British growth charts [22]-[24]. Using these foreign charts results in unnecessary diagnosis of some children with low weight or short stature. It is, therefore, necessary that the children of each region be assessed with the local indices of their own region. Nowadays, high BMI poses an important challenge for healthcare in Iran and worldwide. Changes in lifestyle and dietary habits have elevated the prevalence of obesity in children. In addi- 
tion, thinness and low weight has also increased significantly among Iranian children. Considering the importance of the issue and the fact that the optimal time to prevent the transformation of childhood obesity to adult obesity is 7 - 12 years of age [21]-[25], we conducted the present study to determine the prevalence of obesity in elementary school children of Piranshahr in the first semester of 2012, using BMI and comparing it to the CDC chart, as implemented in many previous studies.

\section{Materials and Methods}

In a descriptive-analytic, cross-sectional study, we assessed 1803 school children aged 7 - 11 years in Piranshahr (comprising 932 boys and 871 girls). Sampling was accomplished through multistage clustered sampling were all elementary schools of Piranshahr, with one public and one private school for boys and girls were selected from each district and one class from each grade (one through fifth) was selected, and all the students in the class). The students in the class were measured for height, weight, waist circumference, hip circumference, and BMI. Other information such as age, number of siblings, parental education and occupation, area of residence, having breakfast, having snacks, regular exercise, and history of obesity in family were recorded through a questionnaire completed in an interview. The students' height was measured without shoes in upright position using a Seca stadiometer with $0.1 \mathrm{~cm}$ precision. Weight was measured using spring scales with $0.1 \mathrm{Kg}$ precision and with minimal clothing. BMI was calculated by dividing the weight (in $\mathrm{Kg}$ ) by height squared (in $\mathrm{m}^{2}$ ). As there are specific BMI charts for each age and sex at 2 - 12 years of age, the cutoff points for obesity and overweight differ for each sex. Therefore, we determined the values for each sex, and then compared the child's BMI to the cutoff point to assess his/her obesity or overweight. We used the percentile reported by Center for Disease Control (CDC) for this purpose. BMI values above the $95^{\text {th }}$ percentile for the respective age and sex were labeled obese and those between $85^{\text {th }}$ and $95^{\text {th }}$ percentiles were deemed overweight. As abdominal obesity is important in adolescents, the following ratios are used to define it:

1. The waist to hip ratio (WHR) calculated by dividing the waist circumference (cm) by hip circumference (cm). Values above 0.1 for boys and 0.9 for girls ( 0.85 in some sources) denote abdominal obesity.

2. The waist to height ratio (WHR) calculated by dividing the waist circumference (cm) by height $(\mathrm{cm})$. Values above 0.5 (for boys and girls) represent abdominal obesity [26]. Students with a history of endocrine disorders (diabetes, hypo- or hyperthyroidism, and corticosteroid use) were excluded from the study. Statistical analysis was accomplished using SPSS v. 19. In order to use the appropriate test, the normality of data and equality of variances were first studied using Leven and K-S tests, respectively. P values $<0.05$ were considered significant.

\section{Results}

As shown in Table 1, there is a meaningful difference between boys and girls in terms of nutrition status of BMI ( $\mathrm{P}<0.0001)$ in that 28 girls (3.2\%) were below the fifth percentile while only 3 boys $(0.3 \%)$ were underweight.

After studying the age and nutrition status of BMI, we found that the percentage of obesity meaningfully decreases as the children grow older $(\mathrm{P}<0.0001)$.

\section{Multivariate Analysis Based on BMI}

In a univariate study of different variables affecting the nutrition status of children in terms of BMI, we observed that five variables of gender, father's job, presence of obese people in the family and father's education meaningfully affected children's BMI. The question is which variables continue to affect BMI after eliminating confounding variables. The answer to the question (BMI status) is nominal-qualitative. Thus, we need to use a linear model for simultaneous assessment of those factors. This will help us enter these meaningful factors one by one through a forward method and examine the newly entered factors with the previous ones in the model. Then, we will be able to check if the new factor is confounding or an independent meaningful factor. Hence, in a relatively long process in the STAT (11.0) statistical software system, we devised the stepwise forward method and finally excluded father's education $(\mathrm{P}=0.78)$ from the final model. Gender, age, father's job and presence of obese people in the family significantly $(\mathrm{P}<0.05)$ and independently remained in the model. It should be noted that they remained in the model so that they would affect the nutrition status in terms of BMI just as assumed in the univariate studies. This means that girls' BMI is still significantly more under the fifth percentile 
Table 1. Economic and social impact of various factors on the nutritional status of children, families and individual children based on BMI.

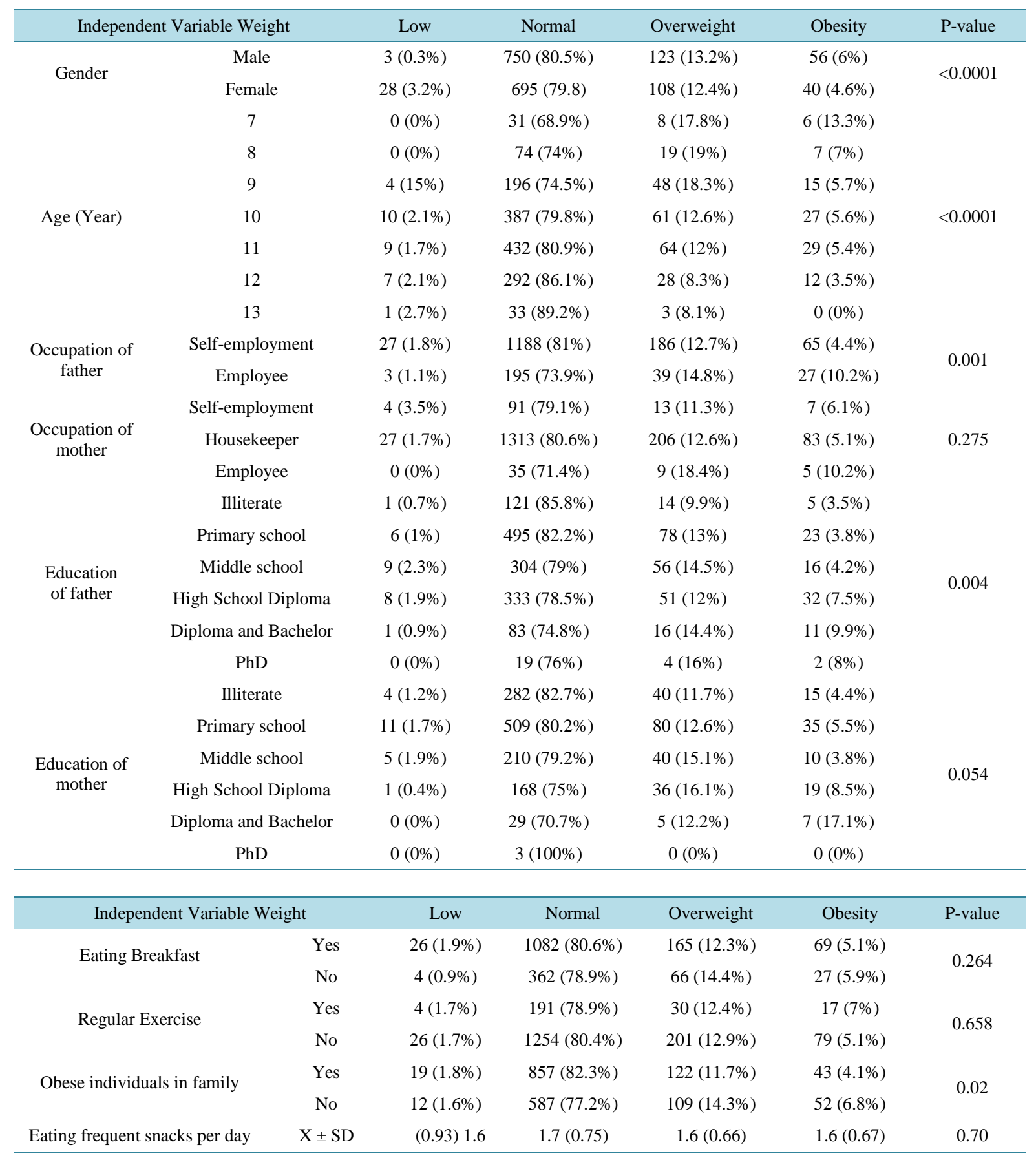

than that of boys. For father's job, age and presence of obese people in the family, the results are the same as the univariate results.

As shown in Table 2, there is a meaningful difference between father's higher education and decreased height in terms of nutrition status $(\mathrm{P}<0.0001)$. Thus, the percentage of shortness decreases with an increase in father's education and shortness increases if there is a history of obesity. In the univariate study of different factors affecting nutrition status in line with the height standard, we observed that the four variables of father's job, presence of obese people in the family, mother's education and father's education meaningfully affect the height of 
Table 2. Influence various economic and social factors on nutritional status of children's families and children, curves Height W.H.O.

\begin{tabular}{|c|c|c|c|c|c|c|}
\hline \multicolumn{3}{|c|}{ Independent Variable } & $\begin{array}{c}\text { (Below the } 5 \text { th percentile) } \\
\text { short stature }\end{array}$ & $\begin{array}{l}\text { (5 - } 90 \text { percentile) } \\
\text { normal }\end{array}$ & (Top 90 percentile) tall & P-value \\
\hline \multirow{2}{*}{ Gender } & \multicolumn{2}{|c|}{ Boy } & $122(13.1 \%)$ & 787 (84.4\%) & $23(2.5 \%)$ & \multirow{2}{*}{0.080} \\
\hline & \multicolumn{2}{|c|}{ Girl } & $116(13.3 \%)$ & 717 (82.3\%) & $38(4.4 \%)$ & \\
\hline & \multicolumn{2}{|c|}{7} & $3(6.7 \%)$ & 40 (88.9\%) & $2(4.4 \%)$ & \\
\hline \multicolumn{3}{|c|}{8} & $11(11 \%)$ & 85 (85\%) & $4(4.4 \%)$ & \\
\hline \multicolumn{3}{|c|}{9} & $28(10.6 \%)$ & $230(87.5 \%)$ & $5(1.9 \%)$ & \\
\hline \multirow[t]{4}{*}{ Age (Year) } & \multicolumn{2}{|c|}{10} & $69(14.2 \%)$ & 403 (83.1\%) & $13(2.7 \%)$ & 0.065 \\
\hline & \multicolumn{2}{|c|}{11} & $63(11.8 \%)$ & 439 (82.2\%) & $32(6 \%)$ & \\
\hline & \multicolumn{2}{|c|}{12} & $51(15 \%)$ & $283(83.5 \%)$ & $5(1.5 \%)$ & \\
\hline & \multicolumn{2}{|c|}{13} & $13(35.1 \%)$ & 24 (64.9\%) & $0(0 \%)$ & \\
\hline \multirow{2}{*}{$\begin{array}{l}\text { Occupation of } \\
\text { father }\end{array}$} & \multicolumn{2}{|c|}{ Self-employment } & 204 (13.9\%) & $1220(83.2 \%)$ & $42(2.9 \%)$ & \multirow{2}{*}{0.008} \\
\hline & \multicolumn{2}{|c|}{ Employee } & $26(9.8 \%)$ & $222(84.1 \%)$ & $16(6.1 \%)$ & \\
\hline \multirow{3}{*}{$\begin{array}{l}\text { Occupation of } \\
\text { mother }\end{array}$} & \multicolumn{2}{|c|}{ Self-employment } & $22(19.1 \%)$ & $90(78.3 \%)$ & $3(2.6 \%)$ & \multirow{3}{*}{0.171} \\
\hline & & reeper & $212(13 \%)$ & 1360 (83.5\%) & $57(3.5 \%)$ & \\
\hline & \multicolumn{2}{|c|}{ Employee } & $3(6.1 \%)$ & 45 (91.8\%) & $1(2 \%)$ & \\
\hline \multicolumn{3}{|c|}{ Illiterate } & $25(17.7 \%)$ & $114(80.9 \%)$ & $2(1.4 \%)$ & \multirow{5}{*}{$<0.0001$} \\
\hline \multicolumn{3}{|c|}{ Primary school } & 94 (15.6\%) & $496(82.4 \%)$ & $12(2 \%)$ & \\
\hline \multirow{3}{*}{$\begin{array}{l}\text { Education of } \\
\text { father }\end{array}$} & \multicolumn{2}{|c|}{ Middle school } & 47 (12.2\%) & 322 (83.6\%) & $16(4.2 \%)$ & \\
\hline & \multicolumn{2}{|c|}{ High School Diploma } & 45 (10.6\%) & 356 (84\%) & $23(5.4 \%)$ & \\
\hline & \multicolumn{2}{|c|}{ Diploma and Bachelor } & $8(7.2 \%)$ & 98 (88.3\%) & $5(4.5 \%)$ & \\
\hline & & & $3(12 \%)$ & $20(80 \%)$ & $2(8 \%)$ & \\
\hline & & rate & $51(15 \%)$ & $283(83 \%)$ & $7(2.1 \%)$ & \\
\hline & & school & $92(14.5)$ & $526(82.8 \%)$ & $17(2.7 \%)$ & \\
\hline Education of & & school & $31(11.7 \%)$ & 220 (83\%) & $14(5.3 \%)$ & $0 \cap 01$ \\
\hline mother & High $\subseteq$ & Diploma & $21(9.4 \%)$ & 188 (83.9\%) & $15(6.7 \%)$ & 0.001 \\
\hline & Diplon & d Bachelor & 3 (7.3\%) & 36 (87.8\%) & $2(4.9 \%)$ & \\
\hline & & & $0(0 \%)$ & 3 (100\%) & $0(0 \%)$ & \\
\hline & $\begin{array}{l}\text { ependen } \\
\text { ariable }\end{array}$ & & $\begin{array}{c}\text { (Below the 5th percentile) } \\
\text { short stature }\end{array}$ & $\begin{array}{l}\text { (5 - } 90 \text { percentile) } \\
\text { normal }\end{array}$ & (Top 90 percentile) tall & P-value \\
\hline Eating Breal & & Yes & $174(13 \%)$ & 1128 (84.1\%) & $40(3 \%)$ & 0211 \\
\hline & & No & 64 (13.9\%) & 374 (81.5\%) & $21(4.6 \%)$ & \\
\hline Regular Exe & & Yes & 27 (11.2\%) & 208 (86\%) & 7 (2.9\%) & 0.520 \\
\hline & & No & $211(13.5 \%)$ & 1295 (83\%) & 54 (3.5\%) & $0.3 \angle 0$ \\
\hline Obese individuals & family & Yes & 153 (14.7\%) & 866 (83.2\%) & 22 (2.1\%) & \\
\hline & & No & 39 (5.1\%) & 636 (83.7\%) & 39 (5.1\%) & -0.0001 \\
\hline
\end{tabular}

children. As it was the case with the study of BMI, this question is raised: which variables continue to independently affect the height of children and the possibility of eliminating confounding variables? The response in question is nominal-qualitative. Thus, we need to use a linear model for simultaneous assessment of those variables. The variable in question is once again a qualitative-nominal one. Therefore, we again need to use linear models modified for simultaneous study of those factors. This will help us enter the meaningful variables into a forward method one by one and compare the newly-entered variable with the previous ones in the model. Then, we will be able to check if the new variable is confounding or independent significant. Hence, in a relatively 
long process in the STAT (11.0) statistical software system, we devised the forward method, and excluded mother's education ( $\mathrm{P}=0.06$ ) from the final model. The three variables of father's job, presence of obese people in the family and father's education significantly $(\mathrm{P}<0.05)$ and independently remained in the model. It should be noted that they remained in the model so that they would affect the nutrition status of children in terms of height just as assumed in the above univariate studies. This means that the children whose fathers had higher education were taller than others. For father's job and presence of obese people in the family, the results were the same as univariate results.

As shown in Table 3, there is a meaningful difference between increased obesity and father's job in that chances that children whose fathers are employees suffer from obesity are higher than those whose fathers are selfemployed. Meanwhile, abdominal obesity is observed among children with a history of obesity $(\mathrm{P}<0.0001)$.

Table 3. Social and economic impact of various factors, family Individual child and the child's nutritional status based on abdominal obesity.

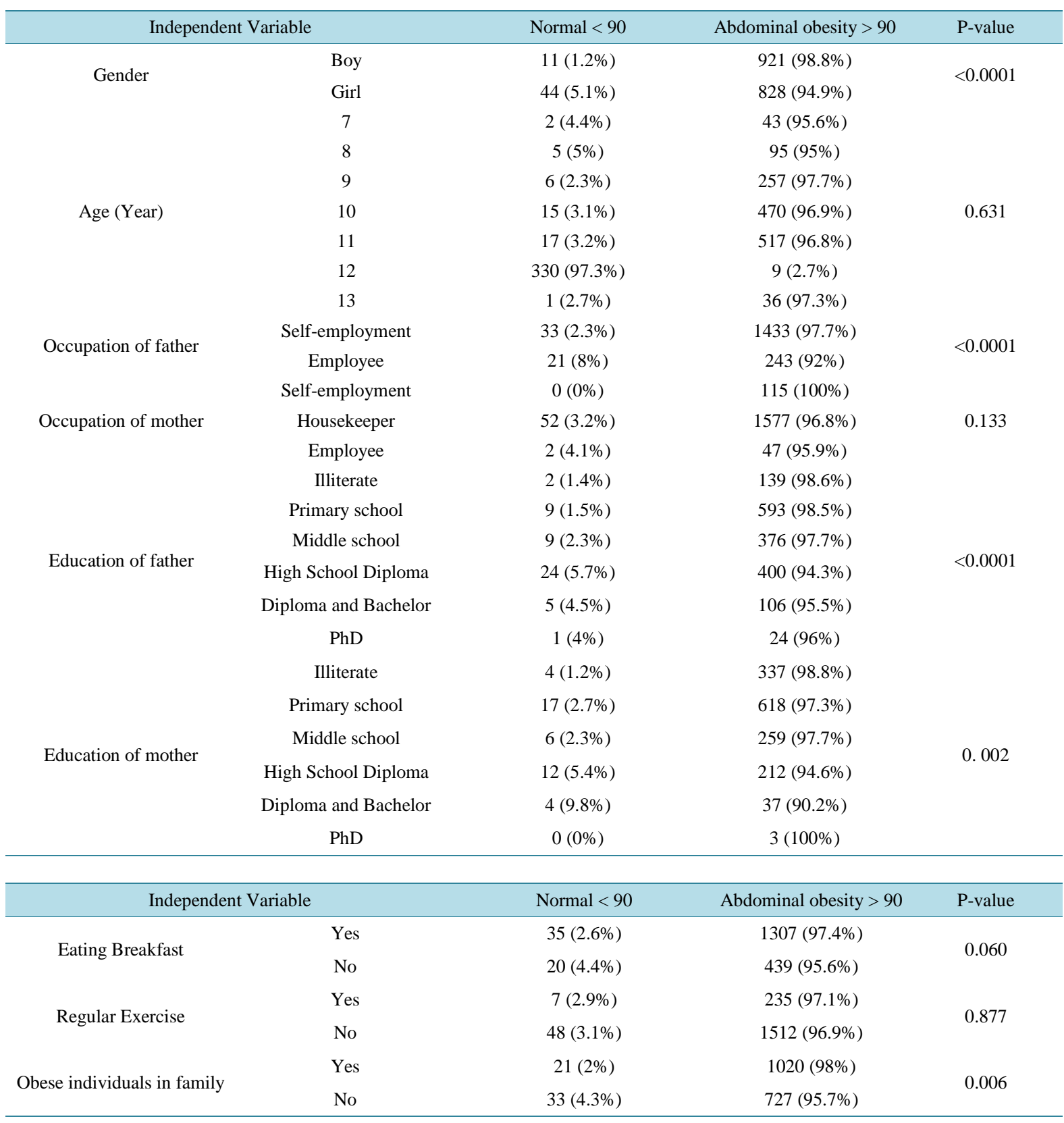


Multivariate analysis based on abdominal obesity. In the univariate study of different variables affecting abdominal obesity, we observed that the five variables of father's job, presence of obese people in the family, mother's education and father's education significantly affected the abdominal obesity incidence among children. The question is which variables continue to independently affect abdominal obesity and the possibility of eliminating confounding factors. Thus, we conducted a multivariate analysis using logistic regression model and backward method. Our findings showed that only the three variables of gender, father's job and presence of obese people in the family independently affected abdominal obesity. Fortunately, we can display a simpler output of the regression model compared to previous models and display OR as per the following table. Thus, abdominal obesity OR of girls equals 4.14 (1.98 - 6.67) compared to boys. Meanwhile, abdominal obesity OR of children whose fathers were employees was 3.84 (2.01 - 7.35) compared to children whose fathers were selfemployed. Meanwhile, Table 4 shows that abdominal obesity OR of children with at least one obese parent or sibling is 2.15 (1.13 - 4.07) times more than those in families with no such people.

Table 5 and Table 6 show that malnutrition exist among school children in Pirnshahr as overweight, obesity, underweight, short stature and abdominal obesity.

\section{Discussion}

The present study showed that 231 children (12.8\%) were at risk of overweight, and 96 children (5.3\%) were overweight. A comparison of our research with other studies shows that although the incidence of overweight and obesity varies in different parts of the world, they are two types of malnutrition that have occurred due to

Table 4. The final model of factors influencing abdominal obesity of children.

\begin{tabular}{|c|c|c|c|}
\hline \multicolumn{2}{|c|}{ Independent Variable } & OR (95\% CI) & P-value \\
\hline \multirow{2}{*}{ Gender } & Boy & 1 & \multirow{2}{*}{$<0.0001$} \\
\hline & Girl & $4.14(1.98-8.67)$ & \\
\hline \multirow{2}{*}{ Occupation of father } & Free & 1 & \multirow{2}{*}{$<0.0001$} \\
\hline & Employee & $3.84(2.01-7.35)$ & \\
\hline \multirow{2}{*}{ Obese individuals in family } & No & 1 & \multirow{2}{*}{0.019} \\
\hline & Yes & $2.15(1.13-4.07)$ & \\
\hline
\end{tabular}

Table 5. Influence various factors on nutritional status of children.

\begin{tabular}{cccc}
\hline Variable & Malnutrition weight & Malnutrition height & Malnutrition abdominal \\
Gender & $<0.0001$ & 0.080 & \\
Age & & 0.0001 & $<0.1000$ \\
Occupation of father & 0.001 & 0.171 & 0.133 \\
Occupation of mother & 0.275 & 0.214 & 0.060 \\
Eating Breakfast & 0.264 & 0.520 & 0.877 \\
Regular Exercise & 0.658 & -- & 0.006 \\
Compared with obese & -- & 0.195 & 0.111 \\
Eating snacks & 0.952 & &
\end{tabular}

Table 6. Distribution of Body Mass Index (BMI).

\begin{tabular}{cc}
\hline Body Mass Index (BMI)* & N (\%) \\
\hline Low weight (below the 5th percentile) & $31(1.7 \%)$ \\
Normal weight (5th to 85th) & $1445(80.1 \%)$ \\
At risk of overweight (85 - 95th) & $231(12.8 \%)$ \\
Overweight (above the 95th percentile) & $96(5.3 \%)$ \\
Tall & $1803(100 \%)$ \\
\hline
\end{tabular}

(m² Length) $/ \mathrm{kg}=$ BMI*. 
nutritional transition. The possible reasons behind the incidence of overweight in this study and other studies can be the sample volume, age group, different age range, different socioeconomic status, and different criteria in diagnosis of obesity or different methodologies. The criteria for diagnosis of obesity and overweight in some studies agree on one point: nutritional transition has revealed its impact in the world and in Iran and even its distant small towns as obesity and overweight. Though, different statistics have been reported in different parts of Iran and other countries. A comparison between the present study and other studies shows that the diagnosis criteria of malnutrition in other studies differ from those of ours. Different studies have shown that not only the incidence of overweight varies in Iran and other parts of the world but also that of underweight and short stature does vary in different researches. In this study, we compared the relationship between malnutrition, overweight and obesity using BMI and short stature using the growth curve and abdominal obesity through waist to hip ratio in light of such factors as gender, age, parents' education level, parents' job and eating breakfast and snacks. Schools can be a suitable place for studying children's growth and also for educating parents and students. Given the rise in non-infectious diseases in society due to changes in people's lifestyle and regarding the increase in the incidence of cardiovascular diseases and also diabetes, it is necessary to pay serious attention to this relationship. Obviously, making plans for this purpose can be considerably helpful for reducing mortality rate as a result of those diseases and for minimizing its heavy costs. If the incidence of short stature in families who suffer from abdominal obesity is higher, we should notify parents so that they would take necessary measures by seeking medical advice in a timely manner. Tall stature among educated fathers is a positive finding. Parents should be educated on this matter, too. The incidence of abdominal obesity is higher among girls than boys because of people's culture in the region. In this regard, schools should play their role to promote sports activities and encourage girls to that effect in line with the Physical Education Department of the city. The incidence of abdominal obesity among children whose fathers are employees is higher than those with self-employed fathers. Thus, we conclude that employee fathers may have bought computers and similar entertainment equipment for their children while they are ignorant about problems caused by sedentary lifestyle. This has paved the way for non-infectious diseases like diabetes, hypertension and cardiovascular diseases. In a study by Padula, the prevalence of obesity based on CDC criteria was 1.1 and 2.33 times higher compared to the WHO and International Obesity Task Force (IOTF) criteria, respectively. Also, obesity based on IOTF criteria was 2.1 times more prevalent compared to the WHO criteria [26]-[30]. In a study by Renzaho on 337 children aged 3 - 12 years, the prevalence of overweight and obesity was $18.4 \%$ and $8.6 \%$, respectively [31]. Comparing different studies with ours reveals that although the prevalence of overweight and obesity varies in different parts of the world and Iran, they both constitute nutritional abnormalities caused by the nutritional transition.

Possible causes for differences in prevalence of overweight in this study and others may be attributed to differences in sample size, sex, age group and age range, socioeconomic status, criteria used for defining obesity and overweight and methodologies utilized. While some studies used the WHO, IOTF and CDC criteria [11] [19] [21] [25] [26] [28], used the criteria defined by Gomez, Waterloo and McLauren [19] [28]. In the present study, we compared the anthropometric characteristics with CDC charts only. Renzaho studied 337 children aged 3 12 years [28], Mozaffari studied 1800 girls aged 1 - 12 years [14], Mahbub studied 480 children [29] and Maia studied 347 children aged 7 - 10 years [30]. We studied 1803 boys and girls aged 7 - 11 years, thus discrepancies can be expected. In Maia's study, nutritional disorder based on CDC criteria was more frequent compared to the NCHS criteria [20]. In general, studies concur on one essential point: the nutritional transition in the world, and consequently even in remote townships of Iran, has affected not only adults, but also children and adolescents with obesity and overweight [11]. In our study, 31 (1.7\%) of children were underweight and 174 (13\%) were short of stature, with the latter being more common in boys than in girls, while underweight was more frequent in girls 28 (3.2\%). This study and others [5] [8] [21] [26] indicate that malnutrition is not completely resolved in different regions of Iran. Comparing our results with those of previous studies indicates that different criteria have been implemented to define malnutrition. The findings suggest that the difference between different regions of Iran and the world is not limited to overweight only, but also includes the prevalence of underweight and short stature. It is possible that factors influencing obesity may also affect the prevalence of underweight and short stature. In other words, differences in age group, sample size, even socioeconomic status and time of the study may account for these discrepancies. Despite all the efforts aimed at improving nutrition, the outcome is still far from the satisfactory point. Nutritional transition in developing countries is associated with overweight [18]. The adverse effect of the current condition must be expected in later years in the adult and middle aged populations, as we also observed more frequent cases of short stature and low weight. Our comparison of 
public and private schools revealed that chronic malnutrition is more frequent in the former, which is consistent with findings of Mozaffari [14]. This may reflect the fact that children in private schools are often in a better socioeconomic status and thus less threatened by malnutrition. Although we did not evaluate the socioeconomic status of children in this study, it is certain the children with better socioeconomic status tend to study in private schools and the difference is not unexpected. Chronic malnutrition (i.e. short stature) was more common in children in public schools, as this condition prevents proper growth in height. As a result, the body mass index, which is influenced by height, will rise and give a higher rate of overweight [21] [25]. Of course, the maximal height growth on the onset of puberty may be able to affect the body mass index [31].

\section{Conclusion}

Using the BMI curve, we studied the height of girls and boys based on the height-age ratio of the WHO and abdominal obesity based on the waist to hip ratio in the city of Piranshahr. We found different degrees of malnutrition in the form of obesity, underweight, short stature and abdominal obesity among school children aged between 7 and 11. We found a meaningful relationship between our findings and the gender and education level of parents and their job as well as having breakfast, eating snacks during the day, history of obesity and regular exercise.

\section{Recommendations}

1. Given the high incidence of abdominal obesity among children whose fathers are employees and the possibility that these children turn to computer games for entertainment, swift and serious measures must be taken to encourage students to take exercises. In this regard, the Physical Education Department of the town should take serious steps to expand sports spaces. Authorities should also explain the sensitivity of the issue to parents. In short, all schools involving teachers and principals must take actions to this end.

2. Father's higher education results in tallness of children. This shows that promoting awareness and education of father is effective in this regard and it is necessary that we devise useful educational programs for the parents through healthcare centers and Department of Education and we should promote those programs at schools. This will absolutely lead to good results.

3. This study found no meaningful relationship between and eating or not eating breakfast. However, one cannot skip this issue easily because we found out that almost all children woke up late and had no time to have breakfast before going to school. It is necessary that parents, particularly mothers, wake up early with their children and eat breakfast with them. This will certainly have a positive effect on children's liveliness in school and will even help prevent many diseases related to malnutrition.

4. No meaningful link was found, either, with regard to snacks. However, eating snacks in school according to the guidelines of the Ministry of Health must be taken seriously. Healthcare centers must take necessary measures in this regard in coordination with the Departments of Education in small cities.

5. Regular exercise in school must be taken seriously due to the problems resulting from obesity. This is because the burden from non-infectious diseases can cause irreparable damage to the society in future.

6. Families with a history of obesity should pay more attention to children regarding short stature and obesity.

\section{Ethical Considerations}

Ethical issues (including plagiarism, informed consent, misconduct, data fabrication and/or falsification, double publication and/or submission, redundancy, etc.) have been completely observed by the authors.

\section{Acknowledgements}

This research is based on post graduate doctoral proposal of Dr. Ali Reihani in health care management. We wish to thank the Research Department of Tehran University of Medical Sciences for financial support. We appreciate the kind collaboration of all the managers and students in elementary schools of Piranshahr for careful completion of our questionnaires.

\section{References}

[1] Popkin, B.M., Adair, L.S. and Ng, S.W. (2012) Global Nutrition Transition and Thepandemic of Obesity in Develop- 
ing Countries. Nutrition Reviews, 70, 3-21. http://dx.doi.org/10.1111/j.1753-4887.2011.00456.x

[2] Gupta, N., Goel, K., Shah, P. and Misra, A. (2012) Childhood Obesity in Developing Countries: Epidemiology, Determinants, and Prevention. Endocrine Reviews, 33, 48-70. http://dx.doi.org/10.1210/er.2010-0028

[3] De Onis, M., Blossner, M. and Borghi, E. (2010) Global Prevalence and Trends of Overweight and Obesity among Preschool Children. The American Journal of Clinical Nutrition, 92, 1257-64. http://dx.doi.org/10.3945/ajcn.2010.29786

[4] Ogden, C.L., Caroll, M.D., Curtin, L.R., McDowell, M.A., Tabak, C.J. and Flegal, K.M. (2006) Prevalence of Overweight and Obesity in the United State 1999-2004. JAMA, 295, 1549-1555. http://dx.doi.org/10.1001/jama.295.13.1549

[5] Hart, C.N. and Jelalian, E. (2008) Shortened Sleep Duration Is Associated with Pediatric Overweight. Behavioral Sleep Medicine, 6, 251-267. http://dx.doi.org/10.1080/15402000802371379

[6] Mo-Suwan, L., Junjana, C. and Puetpaiboon, A. (1993) Increasing Obesity in School Children in a Transitional Society and the Effect of the Weight Control Program. Southeast Asian Journal of Tropical Medicine and Public Health, 24, 590-594.

[7] Khazai, T. and Nasiri, A. (2007) Comparing the Obesity Risk Factors Obese and Normal Children of Birjand 2006. Dena, Quarterly Journal of Yasuj Faculty of Nursing \& Midwifery, 1, 1-10. (Persian)

[8] Baygi, F., Dorosty, A.H., Roya Kelishadi, R., Qorbani, M., Asayesh, H., Mansourian, M. and Kamal Mirkarimi, K. (2012) Determinants of Childhood Obesity in Representative Sample of Children in North East of Iran. Cholesterol, 10, 1155-1160. http://dx.doi.org/10.1155/2012/875163

[9] Cho, K.B., Park, S.B., Park, S.C., Lee, D.H., Lee, S.J. and Suh, S.J. (1989) The Prevalence Trend of Obesity in Children and Adolescent. Journal of the Korean Pediatric Society, 27, 5-40.

[10] Ho, T.F. (1985) Eleventh Hairdos Memorial Lecture. Childhood Obesity in Singapore Primary School Children: Epidemiological Review and Anthropometric Evaluation. The Journal of the Singapore Paediatric Society, 27, 5-40.

[11] Monasta, L., Lobstein, T., Cole, T.J., Vignerová, J. and Cattaneo, A. (2011) Defining Overweight and Obesity in Pre-School Children: IOTF Reference or WHO Standard? Obesity Reviews, 12, 295-300. http://dx.doi.org/10.1111/j.1467-789X.2010.00748.x

[12] Droomers, M., Gross, R., Schultink, W. and Sastroamidjojo, S. (1995) High Socioeconomic Class Preschool Children from Jakarta, Indonesia Are Taller and Heavier than NCHS Reference Population. European Journal of Clinical Nutrition, 49, 740-744.

[13] Bahrami, H., Sadatsafavi, M., Pourshams, A., Kamangar, F., Nouraei, M., Semnani, S., Brennan, P., Boffetta, P. and Malekzadeh, R. (2006) Obesity and Hypertension in an Iranian Cohort Study: Iranian Women Experience Higher Rates of Obesity and Hypertension than American Women. BMC Public Health, 6, 158. http://dx.doi.org/10.1186/1471-2458-6-158

[14] Moztafary, H. and Nabaie, B. (2002) Prevalence of Obesity and Overweight in Primary School Girls in Tehran, Iran. Payesh Journal of the Iranian Institute for Health Science Research, 1, 15-19. (Persian)

[15] Shahgholian, N., Aein, F. and Deris, F. (2003) 90th Percentile of Body Mass Index (BMI) and Some Obesity Risk Factors among 7-12 Years Old School Children, Chaharmahal \& Bakhtiari, 2002. Shahrekord University of Medical Sciences Journal, 5, 42-48. (Persian)

[16] Doost Mohammadian, A., Keshavarz, S.A., Dorosti, A.R., Mahmoudi, M. and Sadrzadeh, H. (2005) Survey of the Nutritional Status and Relationship between Physical Activity and Nutritional Attitude with Index of BMI-for-Age in Semnan Girl Secondary School, Winter and Spring, 2004. Koomesh, Journal of Semnan University of Medical Sciences, 6, 187-194. (Persian)

[17] Salem, Z. and Vazirinejad, R. (2009) Prevalence of Obesity and Metabolic Syndrome in Adolescent Girls in South East of Iran. Pakistan Journal of Medical Sciences, 25, 196-200.

[18] Said-Mohamed, R., Allirot, X., Sobgui, M. and Pasquet, P. (2009) Determinants of Overweight Associated with Stunting in Preschool Children of Yaounde, Cameroon. Annals of Human Biology, 36, 146-161. http://dx.doi.org/10.1080/03014460802660526

[19] Moayeri, H., Bidad, K., Aghamohammadi, A., Rabbani, A., Anari, S., Nazemi, L., et al. (2006) Overweight and Obesity and Their Associated Factors in Adolescence in Tehran, Iran, 2004-2005. European Journal of Pediatrics, 165, 489-493. http://dx.doi.org/10.1007/s00431-006-0101-8

[20] Mosavi Jazayeri, S.M.H. (2005) Overweight and Obesity among School-Aged Children of Metropolitan Tehran, Iran. Pakistan Journal of Nutrition, 4, 342-344.

[21] Garrow, J.S., James, W.P.T. and Ralph, A. (2000) Human Nutrition and Dietetics. 10th Edition, Churchill Livingstone Press, London, 145-152. 
[22] World Health Organization (2000) Workshop on Obesity Prevention and Control Strategies in the Pacific. Apia, 26-29 September 2000.

[23] Hajian, K.O., Sajjadi, P. and Razavi, A. (2008) Prevalence of Overweight and Underweight among Primary School Students Children Aged 7-12 Years (Babol: 2006). Journal of Babol University of Medical Sciences, 10, 83-91. (Persian)

[24] Baygi, F., Dorosty, A.R., Eshraghian, M.R. and Haghighian Roudsari, A. (2010) Association between Dietary Factors and Obesity in Neishubour School Children. Medical Journal of Mashhad University of Medical Sciences, 52, $226-232$. (Persian)

[25] Taheri, F. (2002) Epidemiologic Study of Obesity in School Age Children in Birjand. Journal of Birjand University of Medical Sciences, 9, 18-22. (Persian)

[26] Padula, G. and Salceda, S.A. (2008) Comparison between References of the Overweight and Obesity Prevalence, through the Body Mass Index, in Argentinean Children. Archivos Latinoamericanos de Nutricion, 58, 330-335. (Spanish)

[27] Grummer-Strawn, L.M., Reinold, C. and Krebs, N.F. (2010) Use of World Health Organization and CDC Growth Charts for Children Aged 0-59 Months in the United States. MMWR Recommendations and Reports, 59, 1-15.

[28] Renzaho, A.M. (2004) Fat, Rich and Beautiful: Changing Socio-Cultural Paradigms Associated with Obesity Risk Nutritional Status and Refuge Children from Sub Saharan Africa. Health \& Place, 10, 105-113. http://dx.doi.org/10.1016/S1353-8292(03)00051-0

[29] Mahboub, S., Gaemmaghami, J., Shraki, M. and Mahdavi, R. (2004) The Study of Nutritional Condition in Children of 6-12 Years Old Asadabadi Area of Tabriz. Aft-e, 6, 25-30. (Persian)

[30] Maia, M.M., Fausto, M.A., Vieira, E.L., Benetton, M.L. and Carneiro, M. (2008) The Prevalence of Malnutrition and Its Risk Factors in Children Attending Outpatient Clinics in the City of Manaus, Amazonas, Brazil. Archivos Latinoamericanos de Nutrición, 58, 234-240.

[31] Farzianpour, F., Rabbani, A., Batabi, A., Rasuli, J. and Amini Kashani, M. (2009) Role of Health Management in Evaluation of Programs Monitoring the Growth of Children Aged 0-5 in Tehran, Iran. Pakistan Journal of Nutrition, 8, 829-834. 
Scientific Research Publishing (SCIRP) is one of the largest Open Access journal publishers. It is currently publishing more than 200 open access, online, peer-reviewed journals covering a wide range of academic disciplines. SCIRP serves the worldwide academic communities and contributes to the progress and application of science with its publication.

Other selected journals from SCIRP are listed as below. Submit your manuscript to us via either submit@scirp.org or Online Submission Portal.
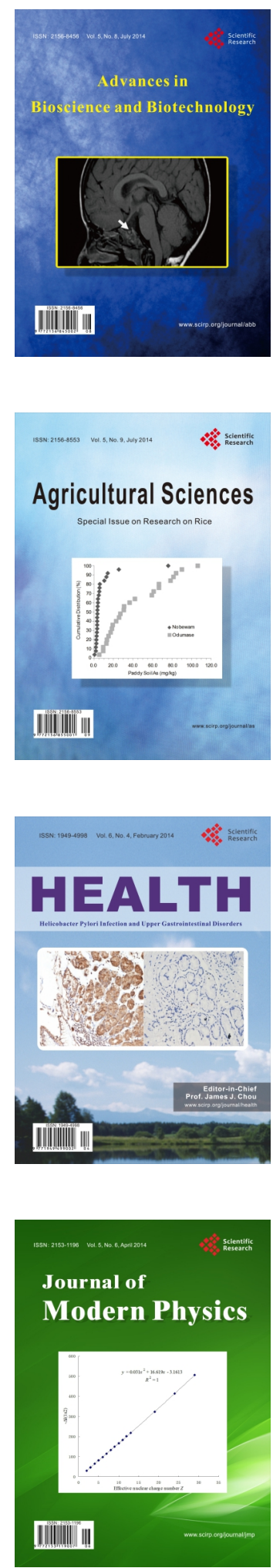
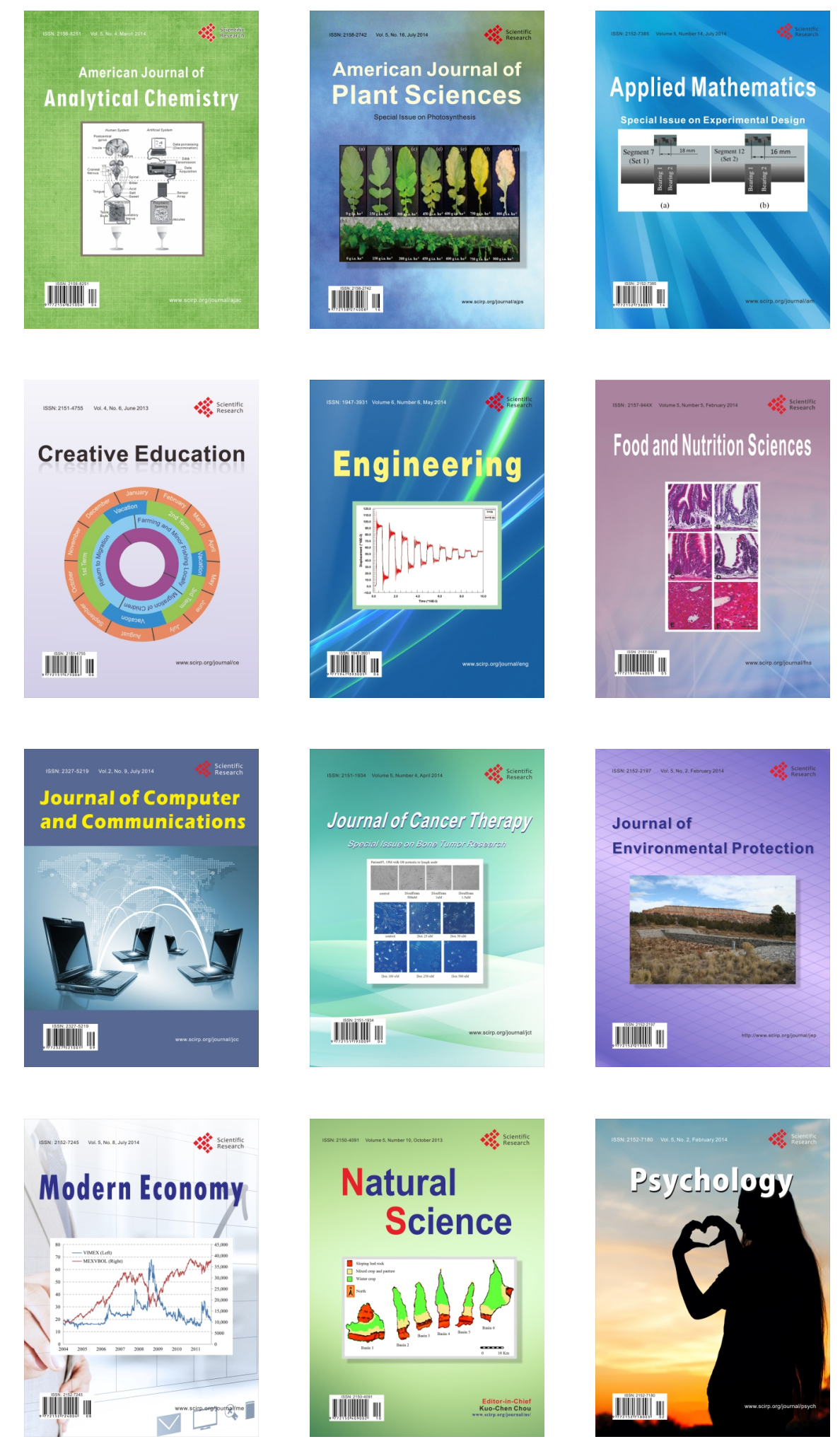